\title{
ANSELMO VIOLA $(* 1738 ; \dagger 1798)$ Y SU CONTEXTO. LA OBRA PARA TECLADO (SONATAS) Y SUS INSTRUMENTOS (ÓRGANO, CLAVICORDIO Y CLAVE) EN LA PENÍNSULA IBÉRICA
}

\author{
ANSELMO VIOLA (*1738; †1798) AND HIS CONTEXT. KEYBOARD \\ OUTPUT (SONATAS) AND ITS INSTRUMENTS (ORGAN, CLAVICHORD AND \\ HARPSICHORD) IN THE IBERIAN PENINSULA
}

\author{
Maria Lluïssa Cortada i Noguero \\ Investigadora Freelance \\ mlluisa2@hotmail.com \\ ORCID iD: https://orcid.org/0000-0001-7125-2027
}

\begin{abstract}
Resumen
El compositor Anselmo Viola $(* 1738 ; \dagger 1798)$ vivió el momento en el que se introdujo en España, con intensidad moderada, el gran ideal de la Ilustración. Compositor, pedagogo y monje del Monasterio de Montserrat en Cataluña (España), su obra incluye: sonatas y música específi ca para órgano; estudios para fagot; y misas y Magnifi cats para coro y orquesta. Me gustaría llamar la atención sobre el Concierto para bajón y orquesta, probablemente, la única obra para solista y orquesta en la Península Ibérica después de las guerras y de la falta de interés intelectual en el patrimonio musical de España.
\end{abstract}

\section{Palabras clave}

Anselmo Viola, Ilustración, Clasicismo, Música de tecla, Sonata, órgano, clavicordio, clave, Península Ibérica

\section{LA MÚSICA EN EUROPA ENTRE LA ILUSTRACIÓN Y EL CLASICISMO}

La crisis que caracteriza buena parte de Europa durante el siglo XVIII determina un movimiento intelectual conocido con el nombre de Ilustración. Su manifestación en cada una de las naciones europeas es de una gran diversidad, aunque presentan, a su vez, una cierta afinidad. Este fenómeno reactivo nace en torno a 1680 y comprende el período que va desde la revolución inglesa de 1688 hasta la Revolución Francesa de 1789. Un

(C) 2018 CSIC. Este es un artículo de acceso abierto distribuido bajo los términos de una licencia de uso y distribución Creative Commons Attribution 4.0 International (CC BY 4.0).

Cómo citar este artículo/Citation: Cortada i Noguero, M. LL. (2018). Anselmo Viola $(* 1738 ; \dagger 1798)$ y su contexto. La obra para teclado (sonatas) y sus instrumentos (órgano, clavicordio y clave) en la Península Ibérica. Anuario Musical, 73: 187-192. doi: http://dx.doi.org/10.3989/redc.2018.73.12

\begin{abstract}
The great ideal of Enlightenment were introduced in Spain with moderate intensity. The composer Anselm Viola (1738-1798) lived at that moment. He was composer, pedagog and monk of Montserrat Monastery of Catalonia (Spain). The corpus of his work introduced: Sonatas and specific music for organ; Studies for fagot; Magnificat and Messes for choir and orchestra. I would like to call your attention to Concert per baixó i orquestra, which is probabily, the only work for soloist and orchestra found in the Península Ibérica after the wars and lack intellectual interest in the musical heritage of Spain.
\end{abstract}

Key words

Anselmo Viola, Enlightenment, Classicism, Keyboard music, Sonata, organ, clavichord, harpsichord, Iberian Peninsula.

siglo caracterizado por el racionalismo, que Batllori califica de revisión crítica ${ }^{1}$.

"En los últimos decenios del siglo XVII, se inició un período de revisión crítica, de revisión científica. Entonces empiezan a surgir los novatores (innovadores) en toda Europa

1 BATLLORI (1964): 85. 
[...] Los novatores eran los que querían renovar la enseñanza de las ciencias, según las investigaciones y los hallazgos de Vesal a finales del XVI en la medicina, y de Descartes y Galileo a comienzos del siglo XVII, en las ciencias fisicomatemáticas. En este momento empieza la Ilustración”.

Las grandes ideas de la Ilustración francesa penetran con una intensidad moderada en la España del despotismo ilustrado. Dentro del ámbito estrictamente musical, la Iglesia fue la conservadora de los archivos y las bibliotecas del patrimonio musical, siendo Montserrat un buen ejemplo. En Cataluña, como en toda Europa, hasta finales del Antiguo Régimen la educación se impartió en el ámbito de las capillas musicales catedralicias y de los monasterios, y de estas escuelas surgieron los músicos profesionales ${ }^{2}$. Georgiades ${ }^{3}$ señala el avance obtenido en relación con las manifestaciones religiosas:

"Ma anche il mutamento del linguaggio musicale produsse un cambiamento sostanziale, [...] la religiosità musicale si secolarizza , fondendosi con l'instinto ludico strumentale. O forse è meglio dire: l'elemento spirituale generale si fonde con l'elemento cristiano".

Por lo que respecta a la dialéctica del contrapunto y la homófona, podemos observar que se consolida un nuevo estilo que estimula diferentes procedimientos y un lenguaje en que el contrapunto es un elemento casi anacrónico. A pesar de los ataques de un sector de la Iglesia, el italianismo se mantiene y definitivamente se pone de relieve la crisis del barroquismo. Alier considera que la ópera motivó la penetración de la música italiana en Cataluña ${ }^{4}$.

\section{ANSELMO VIOLA Y SU ENTORNO HISTÓRICO}

En este contexto histórico, la obra de Anselmo Viola ocupa un lugar destacado: Anselmo Viola $(* 1738 ; \uparrow 1798)$ fue compositor, pedagogo y monje del Monasterio de Montserrat. Nació en Torroella de Montgrí (Girona) y a la edad de diez años ingresó en la Escolanía de Montserrat. Ireneu Segarra, monje del Monasterio de Montserrat, lo califica como

"compositor molt preuat en el seu temps. Conjuntament amb Joan Cererols, Miquel López i Narcís Casanovas con-

2 BONASTRE (1986): 27. “[...] Mancats d'un mecenatge a l'estil italià o alemany, l'Església supleix regularment aquest paper mantenint grups estables de cantors i instrumentistes, i dotant amb regularitat les places d'organista i mestre de capella a les seus catedralícies, basíliques i parròquies importants d'arreu del país". [Traduzco:] "[...] A falta de un mecenazgo a estilo italiano, o alemán, la Iglesia suple regularmente este papel manteniendo grupos estables de cantores e instrumentistas, dotando plazas de organista y maestro de capilla en la sedes catedralicias, basílicas y parroquias importantes del país".

3 GEORGIADES (1989): 128. "La sociedad secularizada, sujeta a la idea del Iluminismo, buscaba, en la función religiosa el elemento agradable, dominical y festivo, la alegría y la diversión".

4 ALIER (1990): 20. formen el grup de compositors més preuats de l'escola Montserratina"5.

En 1758, un año después de profesar la vida monástica, se traslada a Madrid al Monasterio de Nuestra Señora de Montserrat, llamado familiarmente el Montserratico. Cuando Viola llega a Madrid hacía un año que había muerto Domenico Scarlatti (*1685; †1757), y la capilla del monasterio de la Encarnación y la Capilla Real eran el verdadero centro musical de la ciudad. La Capilla Real estaba dirigida por Francisco Courcelle, sucesor de José de Nebra, organista y profesor de clavicémbalo del infante Gabriel. Conviene destacar la incorporación de compositores como Miquel Rabassa (?; †1787), Francisco Moreno y Polo (?; $\uparrow 1766$ ) y los violinistas Francisco Menalt $(* 1715$; $\uparrow 1759)$, Francisco Landini, los flautistas Luis Misón $(? ; \uparrow 1766)$ y otros músicos como Joaquín Oxinaga y Sebastián Albero (*1722; †1756). Este importante grupo de músicos influyó sin duda en la obra de Viola y probablemente a través de ellos asimiló la influencia italianizante. También cabría la posibilidad de contactos con Antonio Soler $(* 1729 ; \uparrow 1783)$, que en aquel momento era monje jerónimo de San Lorenzo de El Escorial.

Alrededor de 1767, Viola regresa al Monasterio de Montserrat con un buen prestigio musical adquirido en Madrid y en 1768 es nombrado maestro de la escolanía y de la capilla de música, cargo que ejercerá hasta su muerte.

El catálogo de Viola es una muestra diversificada de la obra que ha pervivido. En él encontramos:

Obras para teclado: Sonatas, Tientos Partidos, Versos.

Obras para Bajón: Estudios para fagot.

Obras para coro y orquestra: Misas, Magníficat.

Obra orquestal: Concierto para bajón.

Sus obras se encuentran en:

$B b c \quad$ Barcelona, Biblioteca de Catalunya

Boc Biblioteca de l'Orfeó Català

CER Cervera Arxiu Històric Comarcal

$V N \quad$ Arxiu Parroquial de la Geltrú

$G U$ Archivo Musical del Monasterio de Guadalupe

MO Arxiu Històric Musical de Montserrat - Biblioteca de Montserrat, Montserrat

MOsb Arxiu del Monestir de Sant Benet de Montserrat, Montserrat

TAc Tarragona, Arxiu de la Catedral

VI Vic, Museu Episcopal

Este comentario está fundamentalmente dedicado a las piezas para teclado de Anselmo Viola, aunque me gustaría destacar los: Estudios para fagot, técnicamente adelantados para el instrumento del momento, que era el bajón, y el Concierto para bajón, probablemente uno de los pocos conciertos que se han encontrado en la península después de los incendios, las

5 SEGARRA (1968-1969) [núm. 19-20]: 22. “Compositor muy apreciado en su tiempo. Junto con Joan Cererols, Miquel López y Narcís Casanovas conforman el grupo de compositores más apreciados de la Escuela Montserratina". 
guerras sucesivas y el poco interés intelectual hacia la literatura musical del país.

\section{OBRAS PARA TECLADO}

Las obras de Viola para teclado tenían un destino concreto. En unos casos eran piezas organísticas que cumplían una función litúrgica precisa. En otros, como las sonatas, podían intercalarse como complemento de las celebraciones litúrgicas; pero también existían piezas destinadas, probablemente, a las veladas musicales del monasterio con una función pedagógica para los escolanos. Amables, sencillas, sin alardes virtuosísticos, son obras destinadas al órgano, el clavicémbalo o el clavicordio.

Algunas, presentan fórmulas "tocatísticas" claramente adaptadas al órgano; en otros casos, el título ya indica el instrumento: Sonata para órgano, Sonata de $5^{\circ}$ Tono, Sonata para Clarines... Algunas, en tiempo de minueto, podrían ser claramente para el clavicémbalo.

Las sonatas para teclado de Viola, algunas probablemente perdidas, pertenecen a su corpus instrumental y ello nos lleva a un breve comentario sobre el origen y evolución de la sonata hasta finales del siglo XVIII.

\section{ORIGEN DE LA SONATA}

El nombre de sonata surge en la primera mitad del siglo XVII, cuando la música instrumental se independiza de la música vocal. Etimológicamente, el término se refiere a una pieza para tocar, suonare, en contraposición a una pieza para cantar, cantata sin determinar su forma. Las formas fugadas involucradas en el desarrollo de la fuga que aparecen a partir de la imitación de modelos vocales, constituyen el núcleo de la música instrumental de la época; el motete y la chanson francesa fueron los modelos utilizados por el ricercar y la canzona, fusionándose para generar la fuga.

\section{Sonata Cantata}

Praetorius en su Sintagma musicum comenta: "[...] Sonata, Sonada à sonando, wird also genennet / dass is nicht mit Menschen Stimmen/sondern allein mit Instrumenten....”. Una nueva definición nos aporta Mattheson en Der vollkomene Capellmeister: "[...] Die Sonata, mit verschiedenen Violinen oder aufbesondern Instrumenten allein..." .

Inicialmente, como ya se ha comentado, el término sonata sirvió para definir las obras escritas con una finalidad instru-

6 PRAETORIUS (1619): vol. 3, cap. VIII, 21-23. "La sonata/ sonada recibe este nombre porque no está destinada a la voz humana sino a los instrumentos...".

7 MATTHESON (1739): 233. "En la categoría de música instrumental ocupa un lugar importante la Sonata con violines o para un instrumento concreto...". mental, con el fin de diferenciarlas de las dedicadas a la voz. Más tarde este nombre implicó definir una forma; a la segunda mitad del s. XVIII, concretamente con la tríada Haydn, Mozart y Beethoven se consolida la sonata clásica.

\section{LA SONATA EN LA PENÍNSULA IBÉRICA}

Los orígenes de la sonata en la Península parten de la tradición del órgano. Esta circunstancia lleva a Jambou a comentar:

"El tiento utilizando todas las posibilidades de renovación , tejerá la parte más importante de la literatura organística de la Península Ibérica hasta comienzos del siglo XVIII”.

Los orígenes organísticos son recordados por Apel:

"Die frühesten Tientos, in Luys de Milans El Maestro (1535), sind «Studien» in Lautenspiel, ... Beim Übergang zur Orgel nahm das Tiento den Charakter eine Studie im kontrapunktisch-imitatorischen Satz an, wie die ja auch beim Ricercar der Fall war"s.

Sobre la música para teclado es interesante recordar el comentario de S. Kastner:

"Es nuestra opinión que la música española para teclado continuó siempre su propia tradición, pero que empezó a absorber, a mediados del siglo XVIII, influencias extranjeras [...]. La transformación de la tradicional escuela hispánica en escuela italianizada ocupó varios lustros y se efectuó gradualmente. Sin duda, ya antes de la venida de Domenico Scarlatti a la Península, este proceso se encontraba en un estado bastante adelantado".

Francisco Valls, admirador del jesuita Athanasius Kircher [KIRCHER (1650)], utiliza en varias ocasiones el nombre de tiento conjuntamente con los de resercatas, simphonias, conciertos, tocatas y sonatas y, lo clasifica dentro del estilo phantastico:

"Estilo phantástico es una composición desatada, y Methodo libre, y suelto, donde el compositor puede echar por donde quiere; sirve su uso para Música de Órgano, Clavecímbalo, Arpha, Guitarra y cualquiera instrumento que con el solo se pulsen o se tañan tres, ô quatro vozes: Las composiciones de Tientos, Resercatas, Simphonias, Conciertos, Tocatas y Sonatas pertenecen a este Estylo" ${ }^{10}$.

8 APEL (1967): 181-182. "Los primeros Tientos de Luys Milán (El Maestro, Valencia 1535 o 1536), son estudios para laúd. El Tiento al ser trasladado al órgano, toma el carácter de un estudio de contrapunto imitativo con planteamientos similares al Ricercar. En 1555, Bermudo se apropia del término Tiento, especulando con el órgano".

9 KASTNER (1941): 249.

10 PAVIA (2002): cap. XXVII, f. 192-193. 
Es importante la opinión de W. S. Newman ${ }^{11}$ que distingue entre el primer y el segundo estilo galante, clasificando el segundo de antibarroco debido a su propio concepto y carácter.

José Herrando (*1720c; †1763), José de Nebra (*1702; $\lceil$ 1768) — organista de las Descalzas de Madrid - y Francisco Courcelle $(* 1702 ; \uparrow 1778)$, pertenecen al estilo de fórmulas tocatísticas que podríamos enmarcar en el primer estilo galante. Carlos Seixas $(* 1704 ; \dagger 1742)$ - a quien Newman ${ }^{12}$ considera con unas ideas más abiertas que Scarlatti-, y Vicente Rodríguez Monllor $(* 1690 ; \uparrow 1760)$, presentan procedimientos más especulativos y elaboran intentos de factura más moderna.

Es necesario tener presente a Antonio Soler (*1729; $\dagger 1783$ ), que según Newman ${ }^{13}$ pertenece al segundo estilo galante. Las sonatas de Soler, considerado un autor versátil y considerable teórico, cuentan con un referente instrumental del lenguaje de la guitarra con motivos de uno o dos compases sobre un bajo ostinato breve. Soler, discípulo de Elías y posiblemente del propio Scarlatti, utiliza tonalidades más alejadas y una modulación más elaborada. Según Heimes ${ }^{14}$, "las sonatas de Soler que contienen más de un movimiento se pueden considerar un simposio de movimientos [...]. Hay frases asimétricas que acústicamente no lo son".

\section{INSTRUMENTOS DE TECLADO: ÓRGANO / CLAVICÉMBALO / CLAVICORDIO}

El órgano era el instrumento usual y predilecto de Viola. Imprescindible en la laus perennis que, monjes y escolanos dedicaban al culto de la Virgen.

El órgano de la iglesia que existía a comienzos del siglo XVIII, era el resultado de una reforma de Bartomeu Triay que afectó básicamente a la registración y a la composición del órgano mayor. Entre 1737 y 1738 Antoni Boscà lo reformó añadiendo nuevos registros y dos juegos de trompetería horizontal. Entre 1781 y 1785 fue restaurado de nuevo. Era un instrumento de grandes proporciones ideal para la música de Viola según expone Daniel Codina ${ }^{15}$.

Podemos creer que este instrumento perduró, sin otra modificación, más allá de la muerte de Viola, hasta que en 1811, fue destruido en la quema del monasterio por las tropas napoleónicas.

“ [...] y el organista tocando sobre el Canto Llano el Verso que le pertenece, mantiene la cuerda mientras descansa el Coro, y llama la atención para entrar en ella con firmeza el verso siguiente ${ }^{16}$.

11 NEWMAN (1963): 120-121.

12 NEWMAN (1963): 276.

13 NEWMAN (1963): 260.

14 HEIMES (1965).

15 CODINA (1984): Introducció, $X$.

16 NASSARRE (1724): libro III, capítulo 17, 323.

\section{EL ÓRGANO EN LA LITURGIA}

El cambio de estilo que se produce a partir de 1600 otorga una nueva función al órgano dentro el ámbito de la Iglesia. El Caeremoniale episcoporum codifica los atributos litúrgicos de este instrumento, los cuales, al mismo tiempo, incidirán en su evolución ${ }^{17}$.

Con referencia al repertorio ibérico para órgano, destacamos las formas litúrgicas y entre los compositores es significativa la obra extraordinaria de Antonio de Cabezón: Hymnos, Pange lingua, etc. La gran cantidad de versos que se encuentran en los archivos, revelan su funcionalidad. Destaquemos la Salmodia para principiantes de Cabezón y paralelamente el juego de versos, dieciséis, de Viola. Las partes de la misa: Kyrie, Gloria, merecen una consideración especial.

No podemos olvidar la utilidad organística de los ostinatti, ni la riqueza de las formas libres de la danza reagrupadas en rudimentarias suites, como: balletto, corrente, passacaglia o corrente y ciaccona.

\section{CLAVICÉMBALO}

Tenemos mucha información sobre el órgano, pero no sobre el clavicémbalo o el clavicordio. Ignoramos cuántos instrumentos había en el monasterio. Los clavicémbalos, probablemente eran instrumentos pequeños realizados en Barcelona o de factura italiana; en cuanto al clavicordio, sabemos que había diferentes instrumentos en el monasterio y en la escolanía. Ferran Sors menciona una "chambre garnie de clavichordes"18. Por la narración de Ticknesse, que estuvo en Montserrat y visitó algunas celdas de los monjes, recogemos el siguiente comentario:

"They had several good harpsichords as well as good performers beside an excellent organist" ${ }^{\prime 19}$.

Queremos añadir a este comentario una cita de J. G. Sulzer ${ }^{20}$ :

"Quien solo toca o canta correctamente las notas, actúa como el orador que lee su discurso sin ninguna expresión; parecidamente al orador que cambia el tono de su discurso, el músico ha de encontrar la manera de expresar los sonidos".

El estudio de la obra de teclado de Viola plantea diversas cuestiones, siendo una de ellas el instrumento. Para qué instrumento escribió Viola las sonatas: órgano, clavicémbalo, fortepiano...

17 FELLERER (1972): Band II.

18 SOR (1835).

19 TICKNESSE (1778): vol. I.

20 SULZER (1771-1774). 
La estancia de Viola en Madrid permite formular la hipótesis de un posible contacto con la corte, donde podría haber conocido instrumentos de distinta factura, no usuales en el monasterio de Montserrat.

Una última cuestión: cabría preguntarnos por la identificación con la corriente ilustrada por parte de la comunidad monástica de Montserrat, durante los decenios del siglo XVIII y el grado de implicación de sus músicos más ilustres. Probablemente los monjes músicos - Viola, Casanoves, etc. - debían dedicar toda su aplicación a la creación y al trabajo docente, sin participar plenamente en el movimiento intelectual que suponía la Ilustración. Pero no queremos dejar de incorporar la obra y la personalidad de Viola, fruto de una peculiar y avanzada tradición dentro de la corriente conceptual de la Ilustración.

Finalmente, dar a conocer la obra de Viola es una obligación moral. Difundiéndola en todas sus formas: mediante la interpretación pública, y el análisis detallado, puede ayudar a entender el entorno histórico de su autor.

\section{BIBLIOGRAFÍA:}

Alier i Aixelà, Roger, "L'òpera a Barcelona", Orígens, desenvolupament $i$ consolidació de l'òpera com a espectacle teatral a la Barcelona del segle XVIII. Barcelona, Institut d'Estudis Catalans, Societat Catalana de Musicologia, 1990.

Apel, Willi, Geschichte der Orgel- und Klaviermusik bis 1700. Kassel, Bärenreiter, 1967.

Batllori i Munné, Miquel, De l'Edat Mitjana als temps moderns i contemporanis. Vic, Eumo, 1964.

Bonastre i Bertran, Francesc, "El Nadal Barroc català", Revista Musical Catalana, 26 (1986), 27.

Codina i Giol, Daniel, Narcís Casanoves: Obres completes, I. Montserrat, Abadia de Montserrat, col. "Mestres de l'Escolania de Montserrat, XI", 1984.
Fellerer, Karl Gustav, Geschichte der Katholischen Kirchenmusik. Kassel, Bärenreiter, 1972, Band II.

Georgiades, Thrasybulos, Musik und Sprache: Das Werden der abendländischen Musik dargestellt an der Vertonung der Messe. Mit zahlreichen Notenbeispielen. Berlin-Göttingen Springer, 1954 [Musica e linguaggio. Napoli, Guida, 1989].

Heimes, Klaus Ferdinand, Antonio Soler's Keyboard Sonatas. Tesis doctoral, Pretoria, University of South Africa, 1965.

Kastner, Macário Santiago, Contribución al estudio de la música española y portuguesa. Lisboa, Atica, 1941.

Kircher, Athanasius, Musurgia Universalis. Roma, Francesco Corbelletti, 1650.

Mattheson, Johann, Der Vollkommene Capellmeister. Hamburg, Christian Herold, 1739.

Nassarre, fray Pablo, Escuela Música, según la práctica moderna. Zaragoza, Diego de Larumbe, 1724, libro III.

Newman, William S., The Sonata in the Classic Era. Chapel Hill, University of North Carolina Press, 1963, 120-121.

Pavia i Simó, Josep (ed.), Francesc Valls: Mapa armónico práctico (1742a). Barcelona, CSIC, col. "Textos universitarios, 37', 2002.

Praetorius, Michael, Syntagma musicum. 3 vols. Wittenberg \& Wolfenbüttel, Johannes Richter, Elias Holwein 1614-1620. Vol. 3, Wolfenbüttel, Elias Holwein, 1619, cap. VIII.

Segarra i Malla, Ireneu, Breu diccionari biogràfic dels mestres de l'Escolania de Montserrat i els seus col.laboradors. Barcelona, Guia Musical, 1968-1969, núm. 19/20.

Sor, Ferran: "Comentari autobiogràfic", (Ledhuy, Adolphe; y Bertini, Henri, eds.) Encyclopédie Pittoresque de la Musique. Paris, H. Delloye, 1835.

Sulzer, Johann Georg, Allgemeine Theorie der Schönen Künste. 2 vols. Leipzig, M. G. Weidmanns Erben und Reich, 1771-1774.

Ticknesse, Philipp, A year's journey through France, and part of Spain. 2 vols. London, W. Brown, 1778, vol. I.

Recibido: 07.02.2018

Aceptado: 07.02.2018 